\title{
XPS and UPS Valence Band Studies of Nanocrystalline Ni-Ti Alloy Thin Films
}

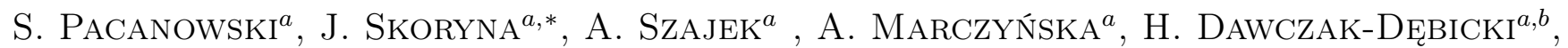 \\ M. WERWIŃSKI ${ }^{a}$, Ł. MAJCHRZYCKI ${ }^{c}$ AND L. SMARDZ ${ }^{a}$ \\ ${ }^{a}$ Institute of Molecular Physics, Polish Academy of Sciences, M. Smoluchowskiego 17, 60-179 Poznań, Poland \\ ${ }^{b}$ Faculty of Physics, Adam Mickiewicz University, Umultowska 85, 61-614 Poznań, Poland \\ ${ }^{c}$ Wielkopolska Centre of Advanced Technologies, Adam Mickiewicz University, \\ Umultowska 89C, 60-614 Poznań, Poland
}

\begin{abstract}
In this contribution we study valence bands of in-situ prepared nanocrystalline $\mathrm{NiTi}$ and $\mathrm{Ni}_{3} \mathrm{Ti}$ alloy thin films using X-ray and ultraviolet photoelectron spectroscopy. Additionally, theoretical valence band of NiTi alloy was calculated by ab-initio methods. The structure and morphology of the samples were studied by X-ray diffraction and atomic force microscopy, respectively. Furthermore, hydrogen absorption and desorption kinetics at a pressure of about 1000 mbar were studied in Pd covered nanocrystalline NiTi alloy thin film using four-point resistivity measurements. Results showed that modifications of the valence bands of the $\mathrm{Ni}$-Ti thin films due nanocrystalline structure can influence on the room temperature hydrogen absorption and desorption kinetics.
\end{abstract}

DOI: 10.12693/APhysPolA.133.613

PACS/topics: 73.22.-f, 68.55.-a, 82.80.Pv

\section{Introduction}

Conventional metal hydrides have the advantages of proper volumetric density, relatively low working pressure, and a reasonable reversibility [1]. In particular, $\mathrm{MgH}_{2}$ has attracted a lot of attention as a solid-state hydrogen storage medium due to its high gravimetric capacity $(7.6$ wt \%) and encouraging reversibility $[2,3]$. However, the main disadvantages preventing the commercial application of $\mathrm{Mg}$ are its high thermodynamic stability, high dehydrogenation temperature and slow kinetics. Many investigations have been carried out to decrease the operation temperature and improve the kinetics through grain size control [4]. Traditional energetic ball milling and cold rolling result in improved hydrogen storage properties because they decrease the grain size, and introduce defects which provide rapid diffusion paths for hydrogen and reduce the diffusion distances [5].

Thin films offer an opportunity to carry out studies on aspects such as average grain size, shape of the interfaces, and composition, because these can be accurately tailored on the nanoscale [6, 7]. During the growth process of thin films average grain size can increase starting from the substrate interface, resulting with many grain boundaries in such samples [8]. Dislocations and vacancies are present in higher density than in bulk material. Even when the grain size is maximized by epitaxial film growth, dislocations are generated during the growth process to adjust for the lattice mismatch between the film and the substrate [9]. The local hydrogen affinity is different for

*corresponding author; e-mail: jskoryna@ifmpan.poznan.pl these defects and therefore the materials properties are expected to be influenced by all these microstructural components.

Furthermore, it is well known, that properties of the nanoparticles change due to the size and surface induced modifications of the electronic structures $[10,11]$. Materials properties are strongly affected by microstructural contributions, therefore the microstructure can be used to tune materials properties for applications. For example, the electrochemical hydrogen properties of NiTi based alloys could be improved by ball milling and annealing [12]. Because of remarkable shape memory effect, pseudoelasticity, corrosion resistance, biocompatibility and excellent mechanical properties [13], the NiTi based alloys have also attracted considerable attention in recent years as functional materials in aerospace engineering, intelligence control, medical implants, etc. In this paper we study experimentally valence bands of nanocrystalline $\mathrm{NiTi}$ and $\mathrm{Ni}_{3}$ Ti alloy thin films using in-situ X-ray (XPS) and ultraviolet (UPS) photoemission spectroscopy. XPS valence band measured for nano-crystalline NiTi thin film was compared to that obtained for ideal single-crystalline alloy using ab-initio calculations. Hydrogen absorption and desorption kinetics were studied in Pd covered $\mathrm{NiTi}$ thin film at room temperature (RT).

\section{Experimental and calculations methods}

Nanocrystalline Ni-Ti alloy thin films were prepared onto oxidised $\mathrm{Si}(100)$ substrates at RT using ultra high vacuum (UHV) magnetron co-sputtering [14-16]. $\mathrm{Ni}$ (99.998 at. \%) and $\mathrm{Ti}$ (99.99 at. \%) targets were sputtered using DC and RF modes, respectively. The total thickness of the alloy thin film samples was about $100 \mathrm{~nm}$. The base pressure before the deposition process 
was lower than $5 \times 10^{-10}$ mbar. As a substrate we have used $\mathrm{Si}(100)$ wafers with an oxidised surface to prevent a silicide formation. Therefore, we have applied a special heat treatment in UHV before deposition in order to obtain an epitaxial $\mathrm{SiO}_{2}$ surface layer [17]. The structure and morphology of the samples have been studied by X-ray diffraction (XRD) and atomic force microscopy (AFM), respectively. The chemical composition and the cleanness of all layers was checked in-situ, immediately after deposition, transferring the samples to the analysis chamber $\left(5 \times 10^{-11}\right.$ mbar $)$ equipped with XPS and UPS. We have used Al-K $\mathrm{K}_{\alpha}(1486.6 \mathrm{eV})$ and He-I $(21.2 \mathrm{eV})$ radiation in the XPS and UPS measurements, respectively. Details of the XPS experiments can be found in Refs. [18-21]. Furthermore, hydrogen absorption and desorption kinetics at RT at a pressure of about 1000 mbar were studied in NiTi (covered by $10 \mathrm{~nm}-\mathrm{Pd}$ ) thin film using four-point resistivity measurements.

The fully relativistic calculations were carried out based on the full-potential local-orbital minimum-basis scheme FPLO (FPLO-14.00-49) [22] with the generalized gradient approximation (GGA) in the Perdew-BurkeErnzerhof (PBE) form [23]. The calculations were performed for the reciprocal space mesh containing 1771 $k$-points within the irreducible wedge of the Brillouin zone. The self-consistent convergence criteria were equal to $10^{-8} \mathrm{Ha}$ for the total energy and for a charge density of $10^{-6}$. The theoretical XPS spectra were obtained from the calculated densities of electronic states convoluted by Gaussian with a half-width $(\delta)$ equal to $0.5 \mathrm{eV}$ and scaled using the proper photo-electronic cross sections for partial states [24].

\section{Results and discussion}

In Fig. 1 we show AFM image $(1 \mu \mathrm{m} \times 1 \mu \mathrm{m})$ of $100 \mathrm{~nm}-$ TiNi thin film. The roughness parameter $R_{a}$ calculated from greater area $(2 \mu \mathrm{m} \times 2 \mu \mathrm{m})$ was as small as $0.11 \mathrm{~nm}$. Average grain size was estimated as $35 \mathrm{~nm}$.

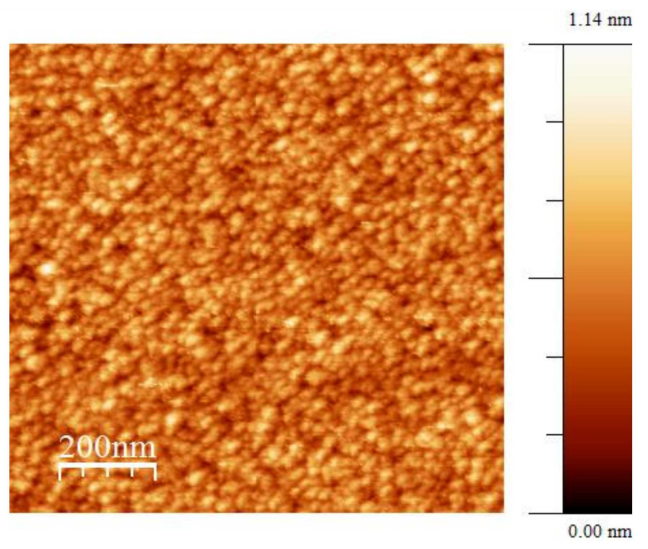

Fig. 1. AFM image of nanocrystalline NiTi alloy thin film.

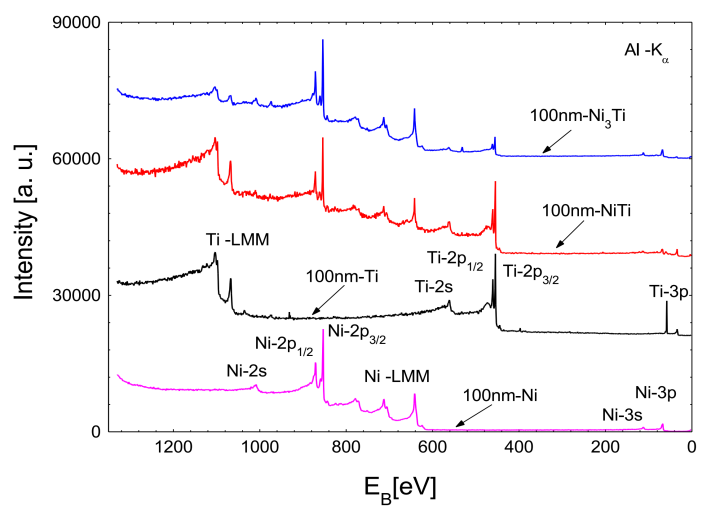

Fig. 2. XPS spectra $\left(\mathrm{Al}-\mathrm{K}_{\alpha}\right)$ of $i n$-situ prepared $\mathrm{Ni}, \mathrm{Ti}$, and nanocrystalline $\mathrm{NiTi}$ and $\mathrm{Ni}_{3} \mathrm{Ti}$ alloy thin films.

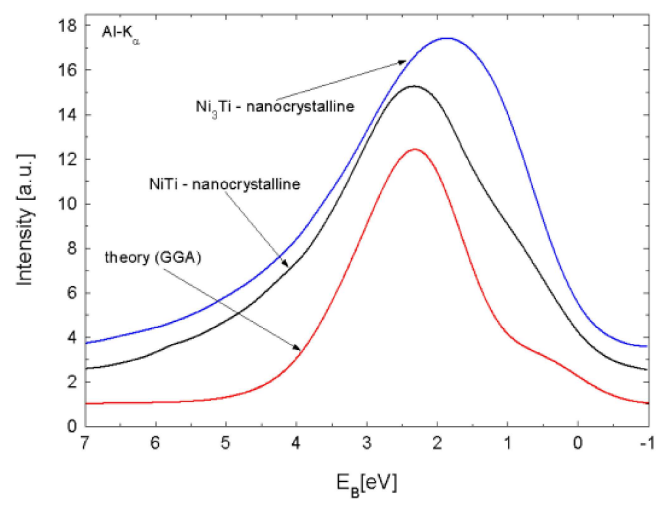

Fig. 3. Experimental XPS valence band spectra of nanocrystalline $\mathrm{NiTi}$ and $\mathrm{Ni}_{3} \mathrm{Ti}$ alloy thin films. For a comparison we also show XPS valence band spectra calculated for single-crystalline $\mathrm{NiTi}$.

Experimental XPS core-level spectra for the freshly prepared nanocrystalline $\mathrm{NiTi}$ and $\mathrm{Ni}_{3} \mathrm{Ti}$ alloy thin films are shown in Fig. 2. For a comparison we also show XPS spectra for pure Ni and Ti thin films. The total thickness of all the prepared thin film samples was about $100 \mathrm{~nm}$. Due to well known high reactivity of titanium with oxygen we have prepared the nanocrystalline alloy thin films after an additional heating of the sample holder and substrate at $700 \mathrm{~K}$ for $3 \mathrm{~h}$ and cooling to $293 \mathrm{~K}$ under UHV conditions. Results showed that after such an outgassing procedure, it is possible to prepare oxygen- and carbonfree surface. The oxygen and other impurities are absent on the surface of such prepared thin films. Practically no XPS signal from potential contamination atoms like O-1s and C-1s is observed (see Fig. 2). On the other hand, we have observed oxygen atoms $(\sim 1$ at.\%) already adsorbed on $\mathrm{Ti}$ based alloy thin film surfaces $3 \mathrm{~h}$ after preparation despite the UHV.

In Fig. 3 we show experimental XPS valence band spectra of nanocrystalline $\mathrm{NiTi}$ and $\mathrm{Ni}_{3} \mathrm{Ti}$ alloy thin films. For a comparison we also show XPS valence band spectra calculated for single-crystalline NiTi alloy within GGA. 
As can be observed, the positions of the experimental spectrum measured for the nanocrystalline NiTi thin film is practically the same as for theoretical XPS spectra. However, the XPS valence band measured for the nanocrystalline sample is considerably broadened compared to those determined by ab-initio calculations (see Fig. 3) or measured for the polycrystalline bulk material $[25]$. Note that the theoretical calculations were performed for the perfect single-crystal structure. Therefore, the broadening of the experimental valence band could be explained by the specific nanostructure of the thin film samples [18-21]. Such a modification of the valence bands of nanocrystalline materials based on Ni-Ti alloys could significantly improve the discharge capacity [26].

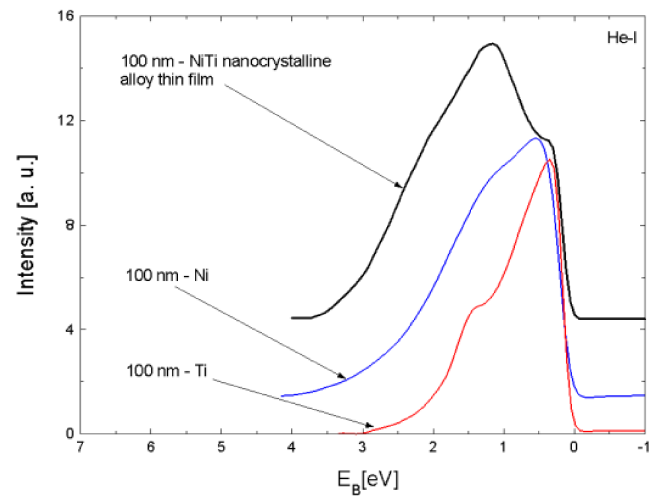

Fig. 4. UPS (He I) valence band spectra of pure $\mathrm{Ni}$ and $\mathrm{Ti}$ thin films and nanocrystalline $\mathrm{NiTi}$ and $\mathrm{Ni}_{3} \mathrm{Ti}$ alloy thin films.

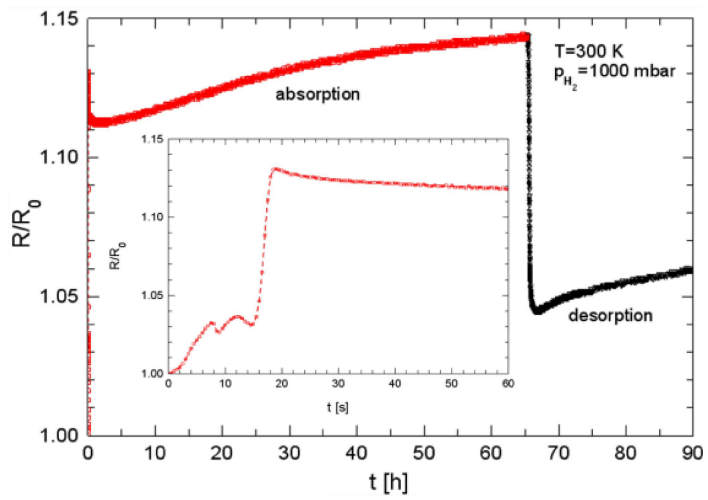

Fig. 5. Hydrogen absorption/desorption kinetics for nanocrystalline $100 \mathrm{~nm}-\mathrm{NiTi}$ alloy thin film. Relative resistance was measured using four-point method at room temperature. The inset shows the first $60 \mathrm{~s}$ of the hydrogen absorption.

Figure 4. shows the experimental UPS valence band spectrum of nanocrystalline NiTi alloy thin film. For a comparison we also show UPS valence band spectra measured for pure $\mathrm{Ni}$ and $\mathrm{Ti}$ thin films. As can be observed, the spectrum measured for the nanocrystalline NiTi thin film is also slightly shifted and broadened compared to that determined for the polycrystalline bulk material [25].

In Fig. 5 we show relative resistivity change of the nanocrystalline $100 \mathrm{~nm}$ - NiTi alloy thin film during hydrogen absorption and desorption at a pressure of about 1000 mbar. Note that immediately after preparation the alloy thin film was covered in-situ by $10 \mathrm{~nm} \mathrm{Pd}$ layer to catalyze hydrogen absorption and to protect against oxidation. The sample shows rather low and two step resistivity change during the first $20 \mathrm{~s}$ of RT absorption (see inset in Fig. 5). On the other hand, the polycrystalline $100 \mathrm{~nm}$ - NiTi alloy thin film coverd by $10 \mathrm{~nm}$ of Pd showed practically no hydrogen absorption (resistivity change). Basing on the in-situ XPS studies (not shown here) any possible contaminations at the $\mathrm{NiTi} / \mathrm{Pd}$ interface can be ruled of as a reason responsible for such an absorption kinetics.

In conclusion, the different microstructure observed in the nano- and polycrystalline NiTi alloy thin film leads to modifications of its electronic structure and as a result can influence on the RT hydrogenation.

\section{Acknowledgments}

The first author (S.P.) would like to thank the Ministry of Science and Higher Education in Poland for financial support within the research project "Diamond grant", 2015-19, No. DI2014010344.

\section{References}

[1] L. Schlapbach, A. Züttel, Nature 414, 353 (2001).

[2] F.E. Pinkerton, B.G. Wicke, Ind. Phys. 10, 20 (2004).

[3] M. Jurczyk, L. Smardz, I. Okonska, E. Jankowska, M. Nowak, K. Smardz, Int. J. Hydrog. Energy 33, 374 (2008).

[4] H. Imamura, K. Masanari, M. Kusuhara, H. Katsumoto, T. Sumi, Y. Sakata, J. Alloys Compd. 386, 211 (2005).

[5] A.D. Rud, A.M. Lakhnik, V.G. Ivanchenko, V.N. Uvarov, A.A. Shkola, V.A. Dekhtyarenko L.I. Ivaschuk, N.I. Kuskova, Int. J. Hydrog. Energy 33, 1310 (2008).

[6] B. Dam, R. Gremaud, C. Broedersz, R. Griessen, Scr. Mater. 56, 853 (2007).

[7] A. Borgschulte, R.J. Westerwaal, J.H. Rector, B. Dam, R. Griessen, Appl. Phys. Lett. 85, 4884 (2004).

[8] M. Ohring, The Materials Science of Thin Films, Academic Press, San Diego 1991.

[9] W.D. Nix, Metall. Trans. A 20, 2217 (1989).

[10] S.K. Sengar, B.R. Mehta, L.K. Malhotra, S.M. Shivaprasad, Appl. Phys. Lett. 98, 193115 (2011).

[11] S.K. Sengar, B.R. Mehta, P.K. Kulriya, S.A. Khan, Appl. Phys. Lett. 103, 173107 (2013).

[12] Z. Zhang, O. Elkedim, Y.Z. Ma, M. Balcerzak, M. Jurczyk, Int. J. Hydrog. Energy 42, 1444 (2017).

[13] K. Otsuka, X. Ren, Prog. Mater. Sci. 50, 511 (2005). 
[14] L. Smardz, J. Alloys Compd. 395, 17 (2005).

[15] L. Smardz, K. Smardz, H. Niedoba, J. Magn. Magn. Mater. 220, 175 (2000).

[16] L. Smardz, K. Le Dang, H. Niedoba, K. Chrzumnicka, J. Magn. Magn. Mater. 140-144, 569 (1995).

[17] L. Smardz, U. Köbler, W. Zinn, Vacuum 42, 283 (1991).

[18] L. Smardz, M. Nowak, M. Jurczyk, Int. J. Hydrog. Energy 37, 3659 (2012).

[19] K. Smardz, L. Smardz, M. Jurczyk, E. Jankowska, Phys. Stat. Sol. (a) 196, 263 (2003).

[20] L. Smardz, M. Jurczyk, K. Smardz, M. Nowak, M. Makowiecka, I. Okońska, Renew. Energy 33, 201 (2008).
[21] K. Smardz, L. Smardz, I. Okonska, M. Nowak, M. Jurczyk, Int. J. Hydrog. Energy 33, 387 (2008).

[22] K. Köpernik, H. Eschrig, Phys. Rev. B 59, 1743 (1999).

[23] J. P. Perdew, K. Burke, M. Ernzerhof, Phys. Rev. Lett. 77, 3865 (1996)

[24] J. J. Yeh, I. Lindau, At. Data Nucl. Data Tables 32 , 1 (1985)

[25] S. Shabalovskaya, A. Narmonev, O. Ivanova, A. Dementjev, Phys. Rev. B48, 13296 (1993).

[26] A. Szajek, M. Makowiecka, E. Jankowska, M. Jurczyk, J. Alloys Compd. 403, 323 (2005). 